\title{
BMJ Open Quantifying Queensland patients with cancer health service usage and costs: study protocol
}

\author{
Emily Callander, ${ }^{1}$ Stephanie M Topp, ${ }^{1,2}$ Sarah Larkins, ${ }^{1,3}$ Sabe Sabesan,, ${ }^{3,4}$ \\ Nicole Bates ${ }^{2}$
}

To cite: Callander $\mathrm{E}$, Topp SM, Larkins S, et al. Quantifying Queensland patients with cancer health service usage and costs: study protocol. BMJ Open 2017;7: 014030. doi:10.1136/bmjopen-2016014030

- Prepublication history for this paper is available online. To view these files please visit the journal online (http://dx.doi.org/10.1136/ bmjopen-2016-014030)

Received 25 August 2016 Revised 8 December 2016 Accepted 20 December 2016

For numbered affiliations see end of article.

Correspondence to Dr Emily Callander; emily.callander@jcu.edu.au

\section{ABSTRACT}

Introduction: The overall mortality rate for cancer has declined in Australia. However, socioeconomic inequalities exist and the out-of-pocket costs incurred by patients in Australia are high compared with some European countries. There is currently no readily available data set to provide a systematic means of measuring the out-of-pocket costs incurred by patients with cancer within Australia. The primary aim of the project is to quantify the direct out-of-pocket healthcare expenditure of individuals in the state of Queensland, who are diagnosed with cancer.

Methods and analysis: This project will build Australia's first model (called CancerCostMod) of outof-pocket healthcare expenditure of patients with cancer using administrative data from Queensland Cancer Registry, for all individuals diagnosed with any cancer in Queensland between 1 July 2011 and 30 June 2012, linked to their Admitted Patient Data Collection, Emergency Department Information System, Medicare Benefits Schedule and Pharmaceutical Benefits Scheme records from 1 July 2011 to 30 June 2015. No identifiable information will be provided to the authors. The project will use a combination of linear and logistic regression modelling, Cox proportional hazards modelling and machine learning to identify differences in survival, total health system expenditure, total out-of-pocket expenditure and high out-of-pocket cost patients, adjusting for demographic and clinical confounders, and income group, Indigenous status and geographic location. Results will be analysed separately for different types of cancer.

Ethics and dissemination: Human Research Ethics approval has been obtained from the Townsville Hospital and Health Service Human Research Ethics Committee (HREC/16/QTHS/110) and James Cook University Human Research Ethics Committee (H6678). Permission to waive consent has been sought from Queensland Health under the Public Health Act 2005.

\section{INTRODUCTION}

In Australia, the overall mortality rate for cancer declined by $20 \%$ between 1982 and 2014. ${ }^{1}$ Among Australians, however, differences still remain in the likelihood of survival

\section{Strengths and limitations of this study}

- Census of Queensland Cancer Registry.

- Linkage of administrative data.

- Data obtained for one state of Australia.

- No inclusion of indirect costs.

depending on socioeconomic status: $13 \%$ of cancer deaths were attributable to socioeconomic inequalities. ${ }^{2}$ Differences in incidence and survival are also reported in Australia according to geographical location, ${ }^{3-7}$ and Indigenous status. ${ }^{3}{ }^{8-10}$ In Australia, these population groups commonly overlap, with a greater proportion of Indigenous Australians residing in remote and very remote areas, ${ }^{11}$ and a greater proportion of Australians living in rural and remote areas experience disadvantage with respect to education, employment, and access to goods and services. ${ }^{12}$

Part of understanding these discrepancies may involve quantifying out-of-pocket healthcare costs. Within Australia, 21\% of patients with cancer have stated they miss care due to the cost. ${ }^{13}$ If a treatment imposes significant financial strain on families then this may affect their decisions to access care. Being able to quantify the out-of-pocket costs faced by patients with cancer is a vital yet currently missing component of understanding the impact of cancer on patients' lives, socioeconomic disparities in clinical outcomes, and the patients' journey through the healthcare system. Currently, there is no systematic and robust means of measuring total out-of-pocket medical expenses of patients with cancer that does not rely on self-reported data. This project seeks to fill this gap.

Australia has a universal healthcare system, Medicare, which provides the population with access to essential healthcare services at no charge to the end user or for a subsidised fee. ${ }^{14}$ Additional private health insurance is 
optional. Access to care in public hospitals is generally free of charge; however, any care provided in private hospitals is not covered by Medicare and must be paid by the patient or private health insurance. For care outside of a hospital, some services are 'bulk billed', meaning that the full cost of treatment is billed directly to Medicare and the patients do not face any up-front or out-of-pocket charges. However, many services do have an 'out-of-pocket' charge that is paid for by the patient, this occurs when the fee charged by the service provider is higher than the rebate paid by Medicare. These provider fees for out of hospital care are not regulated, and providers are able to set their own fees. This has led to occurrences where some providers may charge more for certain patients based on their perceived ability to afford care. ${ }^{15}$

It is well established that cancer in particular is a costly chronic health condition. The Costs of Cancer in New South Wales (NSW) report identified a total of $\$ 3.9$ billion in total expected lifetime financial costs (which includes health system and productivity costs) for people diagnosed with cancer in NSW in 2005. The report identified that the individual bears $40 \%$ of these costs. ${ }^{16}$ While this does highlight the extent of the costs faced by patients, the methods used in this report are based on aggregated data rather than individual data. Aggregated data does not allow for estimates to be stratified by patient characteristics, the identification of groups who face disproportionately high costs, or allow for different changes to health funding to be modelled. This is a major weakness as it is recognised that there are large variations in out-of-pocket expenditure between different patients with cancer, ${ }^{17}$ for example between those in rural areas compared with those in major cities. ${ }^{18}$ Using individual level data, as is proposed in this research project, would overcome these weaknesses.

Other studies within Australia of the out-of-pocket costs faced by patients with cancer and their families have the drawback of focusing on small subpopulations, such as those from a specific geographic area or age group. ${ }^{18-20}$ Such studies are unable to produce generalisable results and are also based on self-reported data. ${ }^{21}$ One study has looked at the ability of telehealth to reduce travel costs, ${ }^{22}$ which are a significant component of out-of-pocket costs for patients; ${ }^{20}$ however, this study was only conducted for one small area of Australia. Most cost-effectiveness studies undertaken as a part of clinical trials, both within Australia and internationally, do not take a patient perspective or make specific note of the level of out-of-pocket costs faced by patients ${ }^{23-26}$ and whether this amount would be affordable and sustainable. The Cancer 2015 project $^{27}$ is linking hospital data with Medicare claims records for patients with cancer in Victoria, Australia. However, it is based on recruited patients and is thus subject to recruitment bias, and it is not supplemented with patient's perspectives of treatment and reports of foregone care.

We propose to create a model of health service use and cost called CancerCostMOD, which will include most direct out-of-pocket costs associated with treatment: provider charges for out of hospital services covered by the Medicare Benefits Schedule, pharmaceutical costs for prescription medications covered by the Pharmaceutical Benefits Scheme and over the counter medications, and travel time. The model will fill the gap in health economic practice within the cancer field regarding out-of-pocket costs. It will allow the accurate estimation of current direct out-of-pocket costs faced by patients with cancer in Queensland, Australia by using administrative data.

The aims of this study are:

1. To determine any inequalities (based on income group, Indigenous status and geographic location) in cancer incidence in Queensland, Australia;

2. To quantify any inequalities (based on income group, Indigenous status and geographic location) in health system use and expenditure on cancer in Queensland, Australia, including hospital admitted patient services, out-of-hospital services and prescription pharmaceuticals;

3. To quantify the out-of-pocket healthcare expenditure of individuals in Queensland, Australia who are diagnosed with cancer, and any inequalities (based on income group, Indigenous status and geographic location);

4. To quantify the travel savings associated with telehealth oncology services in Queensland, Australia, and any inequalities (based on income group, Indigenous status and geographic location).

While the overall focus of this study is patient's out-of-pocket expenditure, aims 1 and 2 will provide a baseline description in socioeconomic inequalities in cancer incidence and general health service use.

\section{METHODS}

\section{Study setting}

For its base population, CancerCostMOD will use a census of patients diagnosed with cancer between 1 July 2011 and 30 June 2012, from the Queensland Cancer Registry and thus will not be subject to recruitment bias. It will therefore be able to capture the direct healthcare expenditure of all people diagnosed with cancer in Queensland. Queensland has a relatively large proportion of its population living outside major cities, and a relatively large proportion of its population identifying as Aboriginal and/or Torres Strait Islander. ${ }^{28}$ Such populations have a relatively high risk of developing cancer and are often diagnosed at a late stage, ${ }^{29}$ but can also be under-represented in national surveys. ${ }^{30}$ They also face additional costs in accessing treatment for cancer-direct transport costs, and indirect costs such as loss of income and caring costs due to prolonged time away from home. ${ }^{20}$ As such, Queensland-based data provides an opportunity to capture results from the at-risk and under-represented populations.

\section{Data}

Data from the Queensland Cancer Registry will be provided to Queensland Health, who will then link this data 
with the Queensland Health Admitted Patient Data Collection (QHAPDC) and the Emergency Department Information System (EDIS). The QHAPDC data set records every hospitalisation in Queensland's public and private hospitals and contains variables on comorbidity, private health insurance, hospital type where admitted, and patient type of admission (public or private). The EDIS contains records of each presentation at emergency departments across Queensland. For each of the individuals extracted from the Queensland Cancer Registry, all of their data from the QHAPDC and EDIS will be requested from 01 July 2011 to 30 June 2015, accounting for multiple admissions and presentations.

The combined Queensland Cancer Registry, QHAPDC and EDIS data set will subsequently be linked by the Australian Institute of Health and Welfare (AIHW) with Medicare Benefits Schedule (MBS) and Pharmaceutical Benefits Scheme (PBS) records for 2011, 2012, 2013, 2014 and 2015 using full name, date of birth and address for matching individuals. AIHW will remove all identifying characteristics and return the complete data set to the research group at James Cook University.

The resultant de-identified data set will then be returned to the research group, and contain demographic variables, diagnosis, clinical outcome measures, plus healthcare use and out-of-pocket expenditure as follows.

\section{Queensland Cancer Registry}

The information obtained from the Queensland Cancer Registry will contain patient demographics at diagnosis and information regarding type of cancer, including stage and grade.

\section{MBS and PBS services}

The MBS and PBS claims records contains the MBS item number, PBS item code, and the patient contribution rate paid for each service accessed by the patient.

\section{Hospital use}

The QHAPDC identifies whether a patient was admitted at a private or public hospital, and whether they were admitted as a private or public patient. For individuals who were admitted as an uninsured patient at a private hospital, the cost attributed to their admission will be calculated from the total Australian Refined Diagnostic-Related Group (AR-DRG) cost weights, less any Medicare rebate. The MBS and PBS data contain a flag for whether any costs were incurred during a hospitalisation, which allows the out-of-pocket costs for private patients admitted at private hospitals to also be identified.

The EDIS identifies the triage category assigned to each presentation. The National Efficient Price apportioned to each triage category by the Independent Hospital Pricing Authority will be used to allocate a cost to each presentation to an emergency department.

The research team will then estimate a number of items as follows:
Table 1 Data sources for health service use and cost

\begin{tabular}{|c|c|c|}
\hline Resource item & $\begin{array}{l}\text { Data source for } \\
\text { number of } \\
\text { services }\end{array}$ & $\begin{array}{l}\text { Data source for } \\
\text { cost per service } \\
\text { use }\end{array}$ \\
\hline $\begin{array}{l}\text { PBS } \\
\text { prescriptions }\end{array}$ & $\begin{array}{l}\text { Medicare claim } \\
\text { records }\end{array}$ & $\begin{array}{l}\text { Medicare claim } \\
\text { records }\end{array}$ \\
\hline MBS items & $\begin{array}{l}\text { Medicare claim } \\
\text { records }\end{array}$ & $\begin{array}{l}\text { Medicare claim } \\
\text { records }\end{array}$ \\
\hline $\begin{array}{l}\text { MBS items with } \\
\text { capped services }\end{array}$ & $\begin{array}{l}\text { Australian Health } \\
\text { Survey }\end{array}$ & $\begin{array}{l}\text { Medicare claim } \\
\text { records }\end{array}$ \\
\hline Hospital services & $\begin{array}{l}\text { QHAPDC } \\
\text { EDIS }\end{array}$ & $\begin{array}{l}\text { AR-DRG codes, } \\
\text { Medicare claim } \\
\text { records } \\
\text { IHPA National } \\
\text { Efficient Price }\end{array}$ \\
\hline $\begin{array}{l}\text { Over the counter } \\
\text { medication }\end{array}$ & $\begin{array}{l}\text { Australian Health } \\
\text { Survey }\end{array}$ & $\begin{array}{l}\text { Arrow Prescription } \\
\text { Program }\end{array}$ \\
\hline $\begin{array}{l}\text { Travel-car } \\
\text { expenses }\end{array}$ & $\begin{array}{l}\text { Medicare claim } \\
\text { records }\end{array}$ & $\begin{array}{l}\text { Australian Tax } \\
\text { Office formula }\end{array}$ \\
\hline \multicolumn{3}{|c|}{$\begin{array}{l}\text { AR-DRG, Australian Refined Diagnostic-Related Group; EDIS, } \\
\text { Emergency Department Information System; IHPA, Independent } \\
\text { Hospital Pricing Authority; MBS, Medicare Benefits Schedule; } \\
\text { PBS, Pharmaceutical Benefits Scheme; QHAPDC, Queensland } \\
\text { Health Admitted Patient Data Collection. }\end{array}$} \\
\hline
\end{tabular}

MBS items with a capped number of services: the records of patients who have received the maximum number of allowable services will be identified. Using the 20112012 Australian Health Survey, the average annual number of these services reported by respondents with malignant neoplasms and similar demographic characteristics will be used to estimate the total number of services accessed each year. Out-of-pocket cost per item will be based on the MBS schedule price.

Over the counter medication use: will also be estimated using the 2011-2012 Australian Health Survey from individuals with similar demographic characteristics. Out-of-pocket expenditure amounts paid for over the counter medication will be obtained from the price listed on Arrow Private Prescription Program.

Travel costs: will be estimated based on MBS and PBS data, which lists postcode of residence and postcode of service use, and the Australian Tax Office cents per kilometre formula will be applied to estimate car expenses.

From this point the full range of health system related out-of-pocket healthcare costs will be captured by CancerCostMOD, with data sources for use and cost detailed below in table 1 .

All health services use, regardless of whether it is directly attributable to cancer or not, will be included. This avoids the difficulty in identifying underlying the clinical reason for health service use, and also the risk of overlooking unexpected clinical consequences of cancer. ${ }^{31} 32$

\section{Analysis}

All analysis will be stratified by cancer type, with a focus on the cancers with the highest incidence, to allow for sufficient sample numbers. 


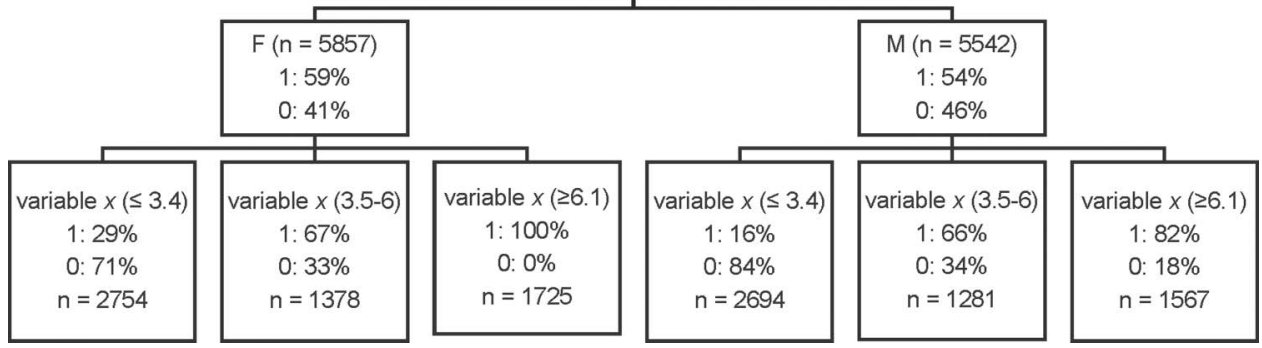

Figure 1 Crude example of decision tree for high-cost patients. This figure shows a crude example of a decision tree, produced by using predictive modelling machine learning. The program identifies the combination of variables that are the biggest predictors of the variable of interest.

\section{Aim 1}

The Queensland Cancer Registry and the 2011 Australian Bureau of Statistics (ABS) National Population Census will be used to calculate the incidence rate of cancer in Queensland. This has previously been done in Queensland; ${ }^{4}{ }^{7}$ however, this project will provide more recent statistics as well as a stratified analysis to identify inequalities by income group, Indigenous status and geography.

\section{Aim 2}

The average health system use (including average annual number of general practitioner consultations, specialist consultations, and hospital admissions) and the associated health system costs per patient will then be quantified for Indigenous and non-Indigenous patients ${ }^{\mathrm{i}}$, income group (those with and without lowincome healthcare cards ${ }^{\mathrm{ii}}$ ), and people living in different geographic areas across Queensland ${ }^{\mathrm{iii}}$ to identify inequalities. The total cost of care for each patient will be divided into quintiles and then further divided into the two highest cost groups.

Decision tree learning will be used to determine if there are any possibly explanatory variables which predict a 'high-cost patient'. This method is a type of predictive modelling machine learning, which enables the user to input multiple variables into the analysis software, such as SAS to produce a decision tree (crude example shown in figure 1). The program identifies the combination of variables that are the biggest predictors of the variable of interest, and splits the data into branch-like segments depending on the rule(s) applied. The hierarchy of the decision tree starts at the root node (top), and splits into the various nodes (branches). ${ }^{33}$

A crude example of what a decision tree might look like is below (figure 1), which shows the probability of a person being a 'high-cost patient'. The values in this

\footnotetext{
${ }^{\mathrm{i}}$ Identified from Queensland Cancer Registry.

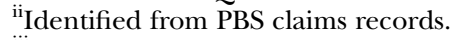

iii Identified from postcodes on Queensland Cancer Registry mapped to Australia/Remoteness Index of Australia.
}

figure are purely as an example, where $1=$ high-cost patient, and $0=$ low-cost patient. The first variable (ie, gender) shows a fairly even distribution of men and women being 'high-cost patients'; however, the second variable $(\mathrm{x})$ shows a difference in the proportion.

Logistic regression will be used to determine the OR of being a 'high-cost' patient. The explanatory variables will be income group, Indigenous status, geographic location, age, sex and any other variables identified in the machine learning phase to be predictive of high cost.

\section{Aim 3}

The differences in patient out-of-pocket healthcare expenditure across different socioeconomic groups will be modelled using linear regression modelling, with a particular focus on difference in out-of-pocket expenditure between Indigenous and non-Indigenous patients, income group, and people living in different geographic areas across Queensland. The outcomes (death and readmission within 30 days) of patients with similar initial clinical characteristics will also be compared for those identified as high or low out-of-pocket expenditure patients, using Cox proportional hazards, and logistic regression models, adjusting for income group, Indigenous status, geographic location, age and sex. This analysis will be conducted using SAS V.9.4.

Geographic analysis will be conducted using SAS V.9.4 and ArcGIS by Primary Health Network (PHN) and Health Service District. The average out-of-pocket cost per patient, adjusted for income group, Indigenous status, geographic location, age and sex, will be identified for each PHN across Queensland.

\section{Aim 4}

The travel cost savings of the telehealth services in Queensland will be determined by analysing the travel costs associated with patients who received any telehealth compared with the travel costs to the patient if this service was not available.

On the basis of the methods published by Thaker et $a l^{18}{ }^{18} 2013$, we will seek to replicate the study across Queensland to analyse the savings conferred by 
telehealth service compared with the counterfactual scenario where teleoncology had not been available.

The outcome of interest is travel cost-savings (continuous numerical variable), a generalised linear model will be used to identify differences in savings associated with teleoncology associated with subpopulation groups (Indigenous and non-Indigenous patients, income group, and people living in different geographic areas across Queensland) adjusting for age and sex.

\section{LIMITATIONS}

While the use of administrative data provides many benefits for analysis, it is acknowledged that certain, mostly indirect costs, will not be captured. This includes costs of productivity loss and carer time. Out of hospital services not covered by the Medicare Benefits Schedule, such as MRIs, will also not be captured.

\section{DISSEMINATION}

Consent will not be sought from participants whose de-identified data will be used in this study. Permission to waive consent has been sought from Queensland Health under the Public Health Act 2005. No identifiable information will be provided to the authors.

A series of reports for each PHN and Hospital and Health Service in Queensland will be developed, outlining the out-of-pocket healthcare expenditure of patients with cancer within their jurisdiction, the impact this has on access care, and relationship with patient outcomes. The project will highlight the potential for the medical profession to directly impact on the living standards of their patients-beyond their health status-by routinely measuring the health system costs of their research, and the out-of-pocket costs to the patient. By presenting the results across each PHN and Health and Hospital Service in Queensland, health professionals working within different jurisdictions will be able to compare how much their patients are paying relative to others.

\section{CONCLUSIONS}

Given the current heightened level of community discussion within Australia about increases to out-of-pocket healthcare costs, it is imperative to know the current, actual out-of-pocket healthcare costs, particularly for patients with cancer for whom it is recognised that out-of-pocket expenditure may be particularly high. ${ }^{16}$ The recent Senate Inquiry into out-of-pocket healthcare expenditure within Australia recommended 'a comprehensive review of the impact of existing co-payments on individuals' access to health services, ${ }^{34}$ which this timely and much-needed project will go some way towards addressing. This information would allow governments and healthcare providers within Australia to accurately identify how policy changes that affect out-of-pocket healthcare costs will impact on the finances of patients with cancer and their families, their decisions to access care and clinical outcomes.

\section{Author affiliations}

${ }^{1}$ Australian Institute of Tropical Health and Medicine (AITHM), James Cook University, Townsville, Queensland, Australia

${ }^{2}$ College of Public Health, Medical and Veterinary Sciences, James Cook University, Townsville, Queensland, Australia

${ }^{3}$ College of Medicine and Dentistry, James Cook University, Townsville, Queensland, Australia

${ }^{4}$ Department of Medical Oncology, Townsville Cancer Centre, Townsville, Queensland, Australia

Contributors EC conceived the original study design. SL and SS contributed clinical expertise to the study design. SMT contributed health systems expertise to the study design. EC and NB will undertake the statistical analysis. All authors have read and approved the final study design.

Competing interests None declared.

Ethics approval Human Research Ethics approval has been obtained from Townsville Health and Hospital Service Human Research Ethics Committee (HREC) (HREC/16/QTHS/110) and external James Cook University HREC (H6678).

Provenance and peer review Not commissioned; externally peer reviewed.

Open Access This is an Open Access article distributed in accordance with the Creative Commons Attribution Non Commercial (CC BY-NC 4.0) license, which permits others to distribute, remix, adapt, build upon this work noncommercially, and license their derivative works on different terms, provided the original work is properly cited and the use is non-commercial. See: http:// creativecommons.org/licenses/by-nc/4.0/

\section{REFERENCES}

1. Australian Institute of Health and Welfare (AlHW), Australasian Association of Cancer Registries (AACR). Cancer in Australia: an overview 2014. Cancer. Canberra, Australia: AlHW, 2014.

2. Stanbury JF, Baade PD, Yu Y, et al. Cancer survival in New South Wales, Australia: socioeconomic disparities remain despite overall improvements. BMC Cancer 2016;16:48.

3. Australian Institute of Health and Welfare (AIHW), Australasian Association of Cancer Registries (AACR). Cancer in Australia: an overview, 2014. Cancer series no 90 Cat no CAN 88. Canberra, Australia: AIHW, 2014.

4. Cramb S, Mengersen KL, Baade P. Atlas of Cancer in Queensland: geographical variation in incidence and survival, 1998 to 2007. Brisbane, QLD: Viertel Centre for Research in Cancer Control, and Cancer Council Queensland, 2011.

5. Public Health Information Development Unit (PHIDU). An Atlas of Cancer in South Australia: a review of the literature and South Australian evidence of differences in cancer outcomes between metropolitan and country residents, and factors that might underlie such differences: produced for Cancer Council SA. Adelaide: PHIDU, The University of Adelaide, 2012.

6. Bois JP, Clements MS, Yu XQ, et al. Cancer maps for New South Wales 1998 to 2002. Sydney: The Cancer Council NSW, 2007.

7. Baade P, Fritschi L, Aitken J. Geographical differentials in cancer incidence and survival in Queensland: 1996 to 2002. Brisbane: Viertel Centre for Research in Cancer Control, and Queensland Cancer Fund, 2005.

8. Australian Institute of Health and Welfare (AIHW). Australian Burden of Disease Study: impact and causes of illness and death in Aboriginal and Torres Strait Islander people 2011. Australian Burden of Disease Study series no 6 Cat no BOD 7. Canberra: AlHW, 2016.

9. Condon JR, Zhang X, Baade $P$, et al. Cancer survival for Aboriginal and Torres Strait Islander Australians: a national study of survival rates and excess mortality. Popul Health Metr 2014;12:1.

10. Valery PC, Coory M, Stirling J, et al. Cancer diagnosis, treatment, and survival in Indigenous and non-Indigenous Australians: a matched cohort study. Lancet 2006;367:1842-8.

11. Australian Bureau of Statistics (ABS). Australian Social Trends, 2014. ABS Cat No 41020. Canberra: ABS, 2014.

12. Australian Institute of Health and Welfare (AIHW). Australia's Health, 2016. Australia's health series no 15 Cat no AUS 199. Canberra: AlHW, 2016. 
13. Callander EJ, Corscadden L, Levesque JF. Out-of-pocket healthcare expenditure and chronic disease? Do Australians forgo care because of the cost? Aust J Prim Health 2016, 10.1071/ PY16005.

14. Australian Institute of Health and Welfare (AlHW). Australia's Health 2014. Australia's health series no 14 Cat no AUS 178. Canberra, Australia: AlHW, 2014

15. Johar M, Mu C, Van Gool K, et al. Bleeding hearts, profiteers, or both: specialist physician fees in an unregulated market. Health Econ 2016 10.1002/hec.3317.

16. Access Economics. Cost of Cancer in NSW. Sydney: Cancer Institute of NSW, 2007

17. Gordon LG, Walker SM, Mervin MC, et al. Financial toxicity: a potential side effect of prostate cancer treatment among Australian men. Eur J Cancer Care 2015, 10.1111/ecc.12392.

18. Thaker DA, Monypenny R, Olver I, et al. Cost savings from a telemedicine model of care in Northern Queensland, Australia. Med J Aust 2013;199:414-17.

19. Heath JA, Lintuuran RM, Rigguto G, et al. Childhood cancer: its impact and financial costs for Australian families. Pediatr Hematol Oncol 2006:23:439-48.

20. Gordon LG, Ferguson M, Chambers SK, et al. Fuel, beds, meals and meds: out-of-pocket expenses for patients with cancer in rural Queensland. Cancer Forum: The Cancer Council Australia, 2009.

21. Sabesan S, Kelly J, Evans R, et al. A tele-oncology model replacing face-to-face specialist cancer care: perspectives of patients in North Queensland. J Telemed Telecare 2014;20:207-11.

22. Thaker DA, Monypenny R, Olver I, et al. Cost savings from a telemedicine model of care in northern Queensland, Australia. Med $J$ Aust 2013;199:414-17.

23. Weber DC, Hurkmans CW, Melidis C, et al. Outcome impact and cost-effectiveness of quality assurance for radiotherapy planned for the EORTC 22071-24071 prospective study for head and neck cancer. Radiother Oncol 2014;111:393-9.
24. Schulz TR, McBryde ES, Leder K, et al. Using stool antigen to screen for helicobacter pylori in immigrants and refugees from high prevalence countries is relatively cost effective in reducing the burden of gastric cancer and peptic ulceration. PLOS ONE 2014;9: e108610.

25. Cronin P, Goodall S, Lockett T, et al. Cost-effectiveness of a mailed advance notification letter to increase colorectal cancer screening. Value Health 2013;16:A141.

26. Ouakrim DA, Boussioutas A, Lockett T, et al. Cost-effectiveness of family history-based colorectal cancer screening in Australia. BMC Cancer 2014;14:261.

27. Lorgelly PK, Doble B, Knott RJ, et al. Realising the value of linked data to health economic analyses of cancer care: a case study of cancer 2015. Pharmacoeconomics 2016;34:139-54.

28. Australian Bureau of Statistics (ABS). Population distribution. Australian Social Trends, ABS Cat No 41020. Canberra: ABS, 2008.

29. Australian Institute of Health and Welfare (AlHW). Rural, regional and remote health Indicators of health status and determinants of health. Rural health series, No 9. Canberra: AlHW, 2008.

30. Australian Bureau of Statistics (ABS). Australian Health Survey: Users' Guide, 2011-13. ABS Cat No 4363055001. Canberra: ABS 2012

31. Johnston K, Buxton MJ, Jones DR, et al. Assessing the costs of healthcare technologies in clinical trials. Health Technol Assess 1999;3. https://lra.le.ac.uk/bitstream/2381/1387/1/mon306.pdf

32. Schulman KA, Glick H, Buxton M, et al. The economic evaluation of the FIRST study: design of a prospective analysis alongside a multinational phase III clinical trial. Flolan International Randomized Survival Trial. Control Clin Trials 1996;17:304-15.

33. de Ville B, Neville P. Decision trees for analytics using SAS Enterprise Miner. Cary, NC: SAS Institute Inc, 2013

34. Senate Community Affairs Committee Secretariat. Out-of-pocket costs in Australian healthcare. Canberra: Senate Printing Unit, Parliament House, 2014. 